\title{
The Ethical Imperative to See the Whole Person: A Conversation With Lois Swope
}

Mary Koloroutis, RN, MSN

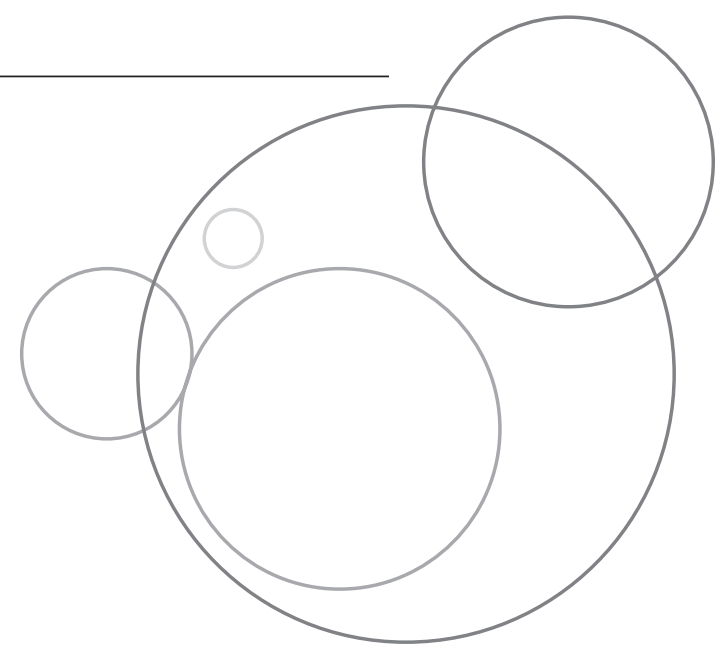

Mary Koloroutis, CEO of Creative Health Care Management, talks with Lois Swope, whose daughter Karly lived with Rett Syndrome until her death in 2012 at age 27. They spoke about the inestimable gifts of Karly's life and the four lessons for people in health care that Lois learned while overseeing Karly's care.

Keywords: Rett syndrome; family-centered care; music therapy; end-of-life decisions

$\mathbf{M}$ ary Koloroutis: Lois, your presentation at our Symposium [the International Relationship-Based Care Symposium presented by Creative Health Care Management in Minneapolis, Minnesota in June 2017] was profound, moving, and warmly received by the health-care professionals attending. Karly's life, and the lessons you learned from her, touched all of us as health-care providers and as people. I think Karly's lessons are universal. First, tell us about Karly and about your journey with her.

Lois Swope: Karly was born in 1985. She was my second child, and everything seemed fine at birth, and for a while nothing seemed unusual other than she was fussier than my first child. Within a few months, however, it became apparent that she wasn't meeting normal developmental milestones. She was very, very unhappy no matter what I did, often crying up to 6 hours daily, for the first 6 years of her life.

What we didn't know then was that she had a disorder called Rett syndrome, which wasn't diagnosed until she was 12 years old. Rett syndrome is described as a combination of symptoms from five other disorders: cerebral palsy, Parkinson's, acute anxiety, epilepsy, and autism. Most children born with Rett syndrome have normal development until they're 2 years old. The first recorded instance of Rett syndrome in the United States was in 1983, only 2 years prior to Karly's birth, so we were often without professional guidance. It was terrifying as a mom, because I had no idea what had happened or how I could help her. She was getting worse instead of better. Rett syndrome had a profound effect on Karly. She never walked independently, never spoke, had seizures, struggled to breathe, often turning blue hundreds of times daily, had limited use of her hands, was legally blind, had acute anxiety, and struggled daily with apraxia.

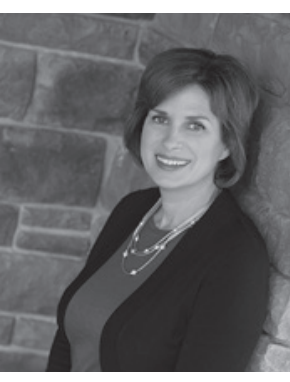

Lois Swope, as Karly's mom and primary caregiver, learned how perseverance, curiosity, and humor helped create a meaningful life of love and peace in the midst of great pain and difficulties. She loves to share her story, hoping it can help and encourage others who work with families like hers.

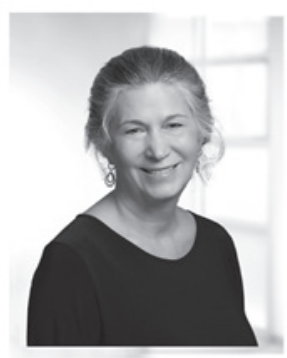

Mary Koloroutis, RN, MSN, is CEO of Creative Health Care Management. 


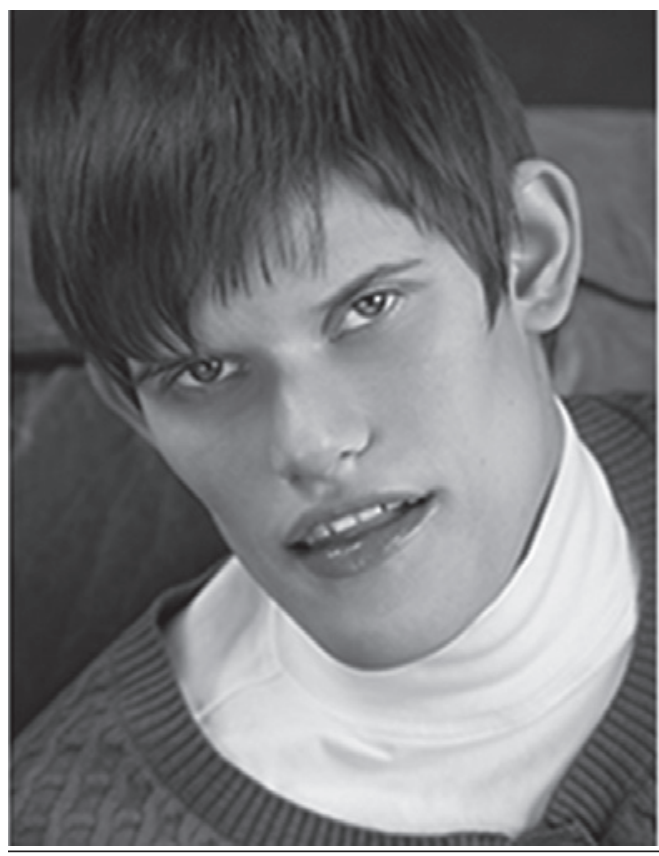

Figure 1 Karly Wahlin.
By the time she was 8 months old, she spent a lot of time looking at her hands and looking at lights through her fingers. At that point, the therapists were saying that she probably had an autism spectrum disorder, but that didn't explain why she wasn't developing in so many other areas. I had to rely almost solely on my maternal instinct for the first 10 years of Karly's life. By the time Karly was 5 years old, we had seen 75 different specialists. None of them gave us hope.

When Karly was 10 years old-before we received the diagnosis of Rett syndrome-we finally discovered a method for her to communicate. I'm grateful in hindsight that we discovered the communication method before she was diagnosed, because there was a belief at that time that girls with her disorder had lost their intellect, along with every other function. We might have found ourselves convinced that she'd never be able to communicate.

After much effort and research, we found an amazing woman who specialized in communication for kids with autism, and Karly started using a keyboard to communicate. Karly demonstrated that she was really, really intelligent by spelling correctly and writing in sentences from the first day. Contrary to her diagnosis of "profound mental impairment," she was not the least bit mentally impaired. Having a voice set Karly free and helped guide our days together. She had the opportunity to tell me what was happening with her body and give me insight about what was important to her.

That's my Karly. She was my best teacher (Figure 1).

Koloroutis: I'm really struck by the notion that not having a diagnosis was a source of so much pain and anxiety and frustration for everyone-however, not having a diagnosis also stopped you from boxing her in. That's really stunning.

Swope: Many parents put a tremendous amount of effort into getting a diagnosis when their child is very young. In some cases it helps with early intervention, or if you're seeking funding or support in a school system. But because a diagnosis of Rett syndrome creates limitations in other people's minds, it would have been a real detriment to Karly. She would never have been given the opportunity to communicate.

Koloroutis: She had a fierce mama watching over her, too. That makes such a difference.

Swope: Desperation is the mother of invention. I liked something you and I discussed in an earlier conversation, which is that no one is born Joan of Arc. We become what our loved ones need as we learn how to become fierce advocates for them. 


\section{LESSON ONE: EVERYONE IS MORE THAN THEIR SYMPTOMS-SEE THE WHOLE PERSON, NOT JUST THEIR DIAGNOSIS}

Koloroutis: At our Symposium, you introduced four lessons for health care workers-lessons you learned through your journey with Karly. Let's start with lesson one, "Everyone is more than their symptoms. See the whole person, not just their diagnosis." This lesson is consistent with what people who work in health care believe is important. They want to give care to the whole person and to really see the human being before them. What does it mean to be seen as a whole person, and what did it feel like when people were seeing Karly as a whole person and when they were not?

Swope: When Karly was very young, our conversations with doctors and therapists and teachers of all types consistently confirmed her limitations. Those conversations usually focused on how long she would live and that she may never speak or walk. To make matters worse, most of these conversations happened in Karly's presence. It grieves me to think of that now. I didn't protect Karly from hearing them because I believed what the professionals were telling me-that Karly was profoundly mentally impaired. Unfortunately, many of us believe it, when we're informed of our child's limitations. This had a damaging effect on both of us. As a small child, long before she could communicate, Karly became agitated when hearing people talk about her.

There was one situation I remember when Karly was about 15 years old and had to have blood drawn. This was an instance when she was definitely not seen as a person. She had tiny little veins, so the blood draw was going to be a big deal even under ideal circumstances. We were sent to the lab by her doctor, and five women showed up; they came into the room and started grabbing Karly's legs and arms, holding her down and twisting her this way and that, trying to keep her still. They were just seeing her as a vein without a person attached to it. It was one of the worst experiences we ever had. They could have listened to me. I knew Karly and I knew her body.

Things that made us feel like someone was really seeing Karly as a whole person included when people managed to ask her good yes/no questions; she could answer those with different movements. We appreciated when people could attune to her and adjust to her mode of communication. Still, a lot of times, people would inadvertently ask questions that were not really clear, such as, "Are you feeling comfortable staying here or would you like to go outside?" That's not really a yes/no question. I think part of seeing someone as a person is making the effort to communicate with them in a way that allows them to give a real answer.

I always saw Karly as a whole person, even as a baby. Once she could communicate, it took an ongoing commitment from me to let her guide us, in order to improve her quality of life. Before that, I was very caught up in managing Karly's symptoms and seeking help. When Karly was 12 years old, I made a commitment to her that I would help her have a full life. From then on, our lives together were enriched by things she loved to do-writing her blog, composing music, sitting by an open window, being outdoors, listening to birds, riding or visiting with her horse. We went from managing her symptoms to enriching her quality of life. A new focus on the things she wanted to do changed her emotional well-being and improved her physical health, too.

\section{LESSON TWO: ASSUME INTELLECT-TRUST THE EXPERIENCE OF THE PATIENT AND THEIR FAMILY}

Koloroutis: That leads into your next lesson, which is, "Assume intellect. Trust the experience of the patient and their family." If the caregivers were partnering with
When people attuned to Karly's method of communicating and asked her good yes/no questions that she could answer with different movements, that made us feel like someone was really seeing her as a whole person. 
you and Karly and trusting that what you would bring to any intervention would help make it work, that would be a much better starting point.

Swope: That's exactly right. Unfortunately, I think we sat in front of very few doctors where I felt like anyone thought Karly could offer anything to the conversation, and they seemed to assume the same thing about me sometimes! Remember that Rett syndrome was very new and not well understood when Karly was young. Doctors have become more familiar with it since then, but we never sat in front of anybody-not even a specialist-who knew more about Rett syndrome than I did-not for Karly's entire life. It put me in the role of always being advocate and teacher. It was a no-win situation though, because if the physician did know about someone with Rett syndrome, that also meant they would assume that Karly was lacking in intelligence and unable to contribute anything helpful.

When Karly was 14, she met a teacher who had a tremendous impact on her life. She recognized Karly's untapped creativity and connected her with a music therapist. That music therapist, Karen Bohnert, developed a method for Karly to compose the music she held in her heart, by choosing one note at a time using cue cards. Each of her 10 songs took up to 2 years to compose with great effort. Karly released a CD of her original piano compositions in 2010; the album beautifully reflects 10 years of painstaking effort.

Karly went from hating school and constantly being too sick to attend, to being well enough to go almost every day. She went with a smile on her face and came home with a smile. She had great joy in being part of a community of people who embraced her, accepted her, and believed in her.

\section{LESSON THREE: EVERY PERSON HAS A BACK STORY. BE CURIOUS AND COMPASSIONATE}

Koloroutis: That brings us to your next lesson: "Every person has a back story. Be curious and compassionate." Tell us what this means to you.

Hearing a health care professional

say, "You're

doing a great

job" carries so

much weight; it's

a really tough life

behind closed

doors, for fami-

lies like ours.

Swope: People outside the family have no idea what parents are dealing with 24 hours a day, 7 days a week. If the child isn't doing well, neither are the parents. One of the best gifts you can give a parent is to check in and ask how they're doing. Often, there are sleepless nights, high medical bills, frustration, fear, blame, and guilt that weigh heavily on us. Do whatever you can to support and encourage these families. When children have profound needs, their parents are often exhausted. This might give context for their fatigue and frustration.

When a child is born with complex needs, their parents are not instant experts. I've heard from many parents how valuable it is for clinicians to say, "You're doing a great job." Hearing that from a health care professional carries so much weight. We are often fearful and hurting. It's a really tough life behind closed doors, for families like ours.

\section{LESSON FOUR: DEATH IS A PART OF LIFE. ACCEPT THAT MORTALITY IS NOT FAILURE}

Koloroutis: Your last lesson is, "Death is part of life. Accept that mortality is not failure." This gets at an internal struggle that many in the helping professions try to cope with, because the message is that we are there to cure and to fix and to make things better. When we're encountering death, we still want to fix it. I'm in- 
terested in your thoughts on that-what you encountered that brought this lesson forward.

Swope: Karly was certainly my teacher when it came to her own end-of-life decisions. It's such a helpless feeling to watch a loved one's health fail.

When she was 26 years old, even with all of our best efforts, Karly's health was unraveling. She is the one who made the decision to stop trying to fix something that wasn't going to be fixed. Karly made it very clear to us that if her heart stopped, she did not want it restarted. It was all part of accepting what was happening to her body. It was shutting down, and she was okay with that. At one point she said, "I'm not trying to die; I'm just accepting what is happening to my body." She had so much peace. She said, "I am ready. I've done what I'm supposed to do here." As a mom, though, and I'm im agining as any professional caregiver, we're not willing to let go-to let things be.

Karly showed us what acceptance looks like without fear or defeat. She taught us that the human-physical part of our life experience has an end, but we are more than that. She wrote a poem that she titled I Am.

I Am

In the quiet of my heart

I am slow.

I breathe deeply.

I sit quietly.

I do not struggle.

I love deeply.

I contribute, I participate.

I speak in ways others can hear.

I am more than my body.

I am.

$$
\sim \text { Karly Wahlin }
$$

I believe all of us are on sacred ground in birth and when transitioning from this life. Something will forever be different and only time will show us how. There's great mystery in it. The hospice caregivers who are at our side providing comfort and care when we're saying goodbye during those agonizing final days and nights offer something sacred. They do hard things every day for people and understand what is normal about the dying process. I didn't know what to expect. There's nothing normal about saying goodbye to your dying child.

One gift that life with Karly has given me is the deep knowledge that every human being has infinite value. Sometimes it takes extra effort to truly see them and what they have to bring us. That kind of love never dies.

Editor's Note: Karly's website is https://spiritdances.wordpress.com/. Her piano CD is available at https:// store.cdbaby.com/Artist/KarlyWahlin

Correspondence regarding this article should be directed to Mary Koloroutis, RN, MSN, at loisswope1@gmail. com 